\title{
Conduction velocity and refractory period of single motor nerve fibres in motor neuron disease
}

\author{
JÖRGEN BORG \\ From the Department of Neurology, Karolinska Hospital, Stockholm, Sweden
}

SUMMARY Electromyographic single motor unit recordings were used to study the axonal conduction velocity and the axonal refractory period of 60 motor units in patients with severe motor neuron disease. Eighteen per cent of the motor units had abnormally low axonal conduction velocity probably due to secondary degenerative changes. Thirty-two per cent of the motor units had abnormally long axonal refractory period but normal conduction velocity. Whether this reflects a primary disease mechanism or secondary changes remains to be established.

Maximal motor and sensory conduction velocities of peripheral nerve trunks are usually normal in motor neuron disease. Only in late stages with significant muscle atrophy is there mild slowing of the maximal motor conduction velocity. ${ }^{1}$ This is usually attributed to loss of alpha motor axons. The pathogenesis of motor neuron disease is unknown. Whether there is a primary neuronopathy or a primary axonopathy or both is debated (see refs 2 and 3 ). No data about the physiological properties of single alpha motor axons in motor neuron disease are available.

Previously the axonal conduction velocity and the axonal refractory period have been determined for single motor units in normal man..$^{4-7}$ In the present study these parameters were studied in single motor units of patients with motor neuron disease.

\section{Materials and methods}

Seventeen patients aged 35-72 years with typical, sporadic motor neuron disease were studied. Disease duration was $1 / 2-3$ years. All patients had signs of generalised lower motor neuron involvement with fasciculations and muscle atrophy.

Electromyographic recordings were made by conventional bipolar needle electrodes (DISA $9013 \mathrm{K0802}$ ). The recordings were selective enough to permit identification of single motor unit potentials even at maximal voluntary effort and after supramaximal electric nerve stimulation. This was due to the loss of motor units and the increased fibre density of the remaining ones. The motor unit poten-

Address for reprint requests: Dr Jörgen Borg Department of Neurology, Karolinska Hospital, S-104 01 Stockholm, Sweden.

Received 19 July 1983 and in revised form 17 October 1983 Accepted 5 November 1983 tials were amplified and displayed on a Medelec oscilloscope (No. 4329) and recorded on Kodak Linograph direct print paper.

Electrical shocks, $0.2 \mathrm{~ms}$ in duration, were delivered proximally to the peroneal nerve close to the fibular head and distally at the ankle. Surface electrodes, $0.6 \mathrm{~cm}$ in diameter were used. The cathode was placed over the nerve and the anode $2-3 \mathrm{~cm}$ medially or lateraly to the cathode. Stimulus strength could be gradually changed from 0 to $100 \mathrm{~mA}$. The needle electrode was adjusted so that the test motor unit potential could be identified in sustained maximal voluntary contraction. The effort was then reduced until the motor unit no longer discharged and the electrical stimuli were delivered. Stimulus strength was $10 \%$ above the resting threshold level. The motor unit identity at proximal and distal stimulation was confirmed by the blocking experiment (point 2 below).

(1) One nerve stimulus was delivered proximally and one distally, the latency difference was calculated and the axonal conduction velocity determined.

(2) One proximal and one distal stimulus were delivered coupled to each other. The proximal testing stimulus was initially delayed $10-15 \mathrm{~ms}$ to permit the distally evoked, antidromic propagated nerve impulse to pass the proximal test point before stimulation there. The stimulus interval was then reduced until the second evoked motor unit potential disappeared due to blocking at the proximal, testing, point during the refractory period after the antidromic impulse. By comparing the shortest stimulus interval without blocking with the previously determined latency difference (point 1 above), the axonal refractory period after an antidromic propagated nerve impulse was calculated. ${ }^{5}$

(3) Paired electrical stimuli were delivered to the nerve at the proximal stimulus point. The stimulus interval was initially $10 \mathrm{~ms}$ and then reduced until the second evoked motor unit potential disappeared in an all-or-none manner due to blocking at the stimulus point during the axonal refractory period. By defining the shortest stimulus interval without blocking, the axonal refractory period after a conditioning electrical nerve stimulus was determined. ${ }^{\circ}$ 
Further, the interval between the evoked motor unit responses was measured at each stimulus interval and the shortest motor unit response interval was determined. ${ }^{\circ}$ When the identification of the second evoked motor unit potential was difficult, because of peripheral blocking, a distal nerve stimulus was introduced (cf. Results).

Room temperature was $23-25^{\circ} \mathrm{C}$. Skin temperature of the lower leg and the foot was carefully controlled and held at $32^{\circ} \mathrm{C}$ by a Disaheater (DISA, Electronic, Skovlunde, Denmark).

\section{Results}

\section{AXONAL CONDUCTION VELOCITY}

Sixty motor units were investigated in the 17 patients. In each patient $1-10$ motor units were studied.

Figure 1 shows the axonal conduction velocities of the 60 motor units together with corresponding data from normal subjects. ${ }^{48}$ In the patients $18 \%(11 / 60)$ of the motor units had axonal conduction velocity below $30 \mathrm{~m} / \mathrm{s}$ while normally less than $1 \%(2 / 222)$ of the motor units had a conduction velocity below this level.

AXONAL REFRACTORY PERIOD FOLLOWING A CONDITIONING PROPAGATED NERVE IMPULSE The axonal refractory period following an antidromic propagated nerve impulse was determined for the 60 motor units using test stimulus strength $10 \%$ above the resting threshold level. The refractory periods ranged from 1.4 to $3.2 \mathrm{~ms}$. In the patients $38 \%(23 / 60)$ of the motor units had axonal refractory periods longer than $2.5 \mathrm{~ms}$ while in normal subjects less than $1 \%(1 / 109)$ had refractory periods longer than this. In 12 of the 17 patients at
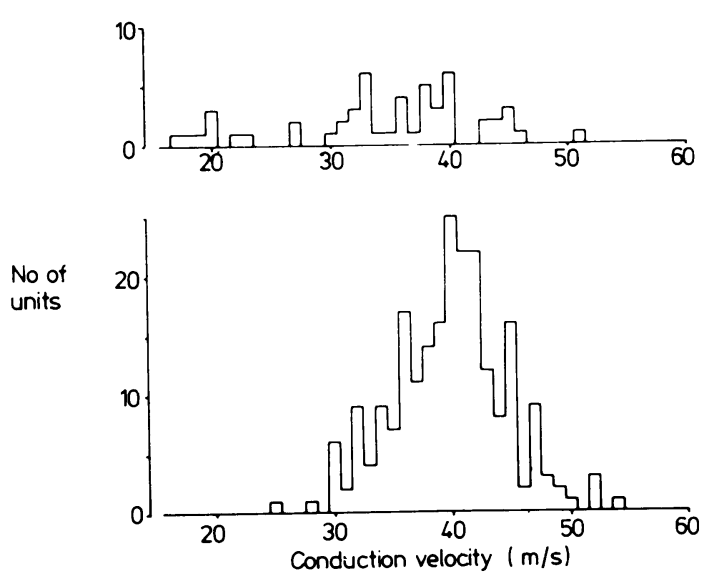

Fig 1 Axonal conduction velocities of $(A), 60$ motor units in patients with motor neuron disease and, $(B), 222$ motor units in normal subjects. least one motor unit with axonal refractory period longer than $2.5 \mathrm{~ms}$ was observed.

Fifty per cent $(30 / 60)$ of the motor units had abnormally low conduction velocity, that is, below $30 \mathrm{~m} / \mathrm{s}$, and/or abnormally long refractory period. that is, longer than $2.5 \mathrm{~ms}$. thirty-two per cent (19) $60)$ had an abnormal refractory period and normal conduction velocity. Twelve per cent $(7 / 60)$ had an abnormal conduction velocity and normal refractory period. Seven per cent $(4 / 60)$ were abnormal in both respects.

Figure 2 shows the individual mean values of the axonal conduction velocities and the refractory periods for the 17 patients together with corresponding data from 22 normal subjects. For the patients these refractory period data exhibited a mean of $2.3 \pm 0.46 \mathrm{~ms}(\mathrm{M} \pm \mathrm{SD})$. The corresponding mean value in normal subjects was $1.9 \pm 0.26$ ms. ' The difference between the mean values was statistically significant $(\mathrm{p}<0.01)$.

\section{SHORTEST MOTOR UNIT RESPONSE INTER VAL}

When paired electrical stimuli are delivered proximally to the peroneal nerve at intervals shorter than $3 \mathrm{~ms}$, the slowing of the conduction of the second impulse propagated during the relative refractory period of the first impulse normally prevents peripheral blockings and limits the motor unit response interval to $3-5 \mathrm{~ms}^{\circ}{ }^{\circ}$

For 20 of the motor units in eight patients, paired electrical stimuli were delivered proximally to the peroneal nerve at stimulus intervals shorter than 3 ms. For $65 \%(13 / 20)$ of the motor units, having axonal conduction velocities $28-43 \mathrm{~m} / \mathrm{s}$, the shortest motor unit response interval ranged from 3.5 to 7.5 $\mathrm{ms}$. For six motor units the interval was longer than $5 \mathrm{~ms}$ which was never observed normally. Three of the six motor units had an abnormally long axonal refractory period at the proximal test point while the other three had refractory periods within normal limits. All six had normal axonal conduction velocity.

Figure 3 shows the individual mean values of the shortest motor unit response intervals and the axonal conduction velocities for seven patients together with corresponding data from normal subjects. ${ }^{\circ}$ The mean value for the patient data, $5.55 \pm$ $1.55 \mathrm{~ms}$, was significantly longer than the corresponding value in normal subjects, which was $4 \cdot 2 \pm$ $0.30(\mathrm{p}<0.01)$.

For $35 \%(7 / 20)$ of the motor units significant peripheral blockings occurred at stimulus intervals shorter than $5 \mathrm{~ms}$.

Figure 4 shows the recordings of a motor unit when paired electrical stimuli were delivered proximally. Figure $4 \mathrm{~A}$ shows that when the stimulus 


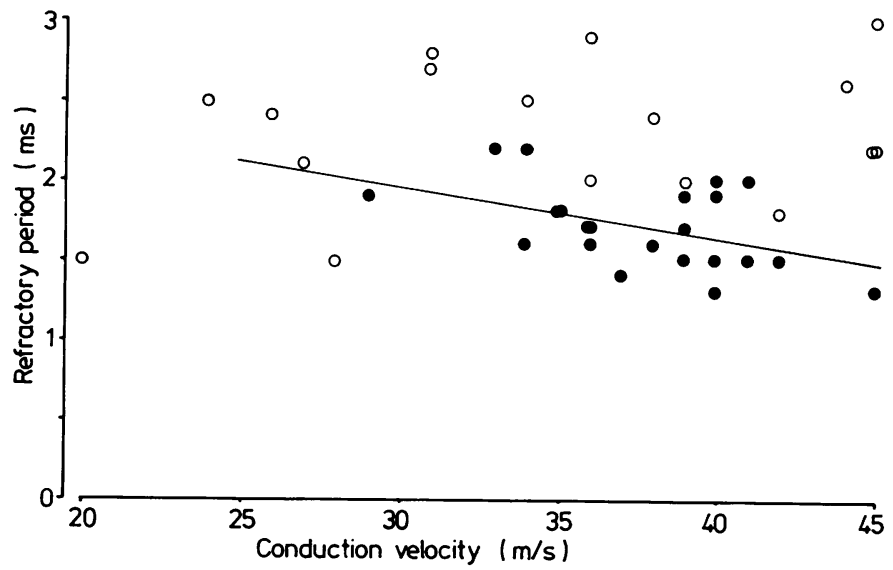

Fig 2 Axonal refractory period and axonal conduction velocity. Mean values for 17 patients with motor neuron disease (open dots) and 22 normal subjects (filled dots). Regression line of normal data marked as illustration.

interval already reached $5 \mathrm{~ms}$, the second evoked motor unit response was delayed in relation to the second stimulus. Figure 4B shows that when the stimulus interval was $3 \mathrm{~ms}$ the second potential almost disappeared. This was due to peripheral blocking because when test stimulus strength was increased the main part of the potential remained blocked. Thus, for this particular motor unit, the shortest response interval after paired electrical nerve stimuli was restricted by peripheral blocking. This was not seen normally. ${ }^{6}$

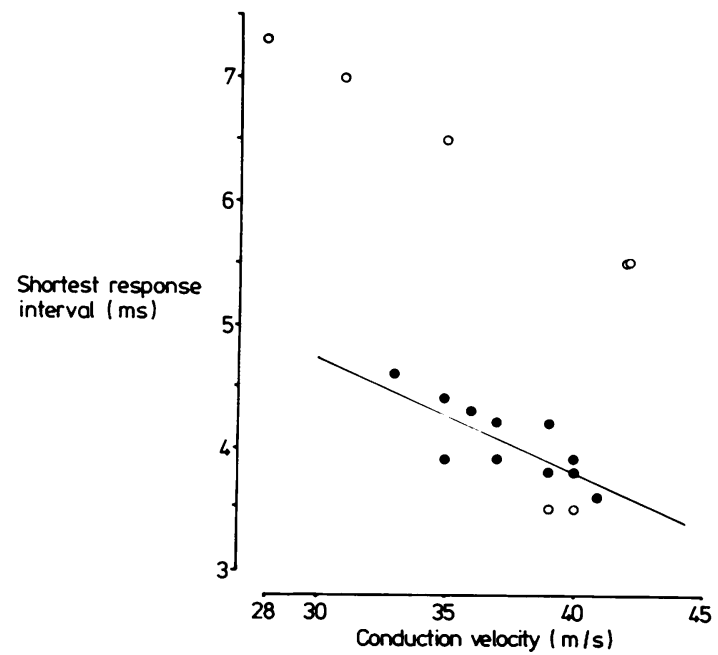

Fig 3 Shortest motor unit response interval after paired electrical nerve stimuli. Mean values of 7 patients with motor neuron disease (open dots) and 11 normal subjects (filled dots).
AXONAL REFRACTORY PERIOD FOLLOWING A CONDITIONING ELECTRICAL NERVE STIMULUS For 20 of the 60 motor units the axonal refractory period was also determined at the proximal test point by using a conditioning electrical stimulus delivered through the same electrode as the testing stimulus. One to six motor units were studied in each of eight patients. Test stimulus strength was $10 \%$ above the resting threshold level. For these motor units, where peripheral blocking restricted the shortest motor unit response interval after paired electrical nerve stimuli (cf. above), the axonal refractory period after a conditioning electrical nerve stimulus could not be determined without introducing a distal nerve stimulus to block the impulse elicited by the first conditioning, proximal stimulus. The recordings from such an experiment are shown in fig $4 \mathrm{C}-\mathrm{D}$. Figure $4 \mathrm{C}$ shows that when the interval between the proximal stimuli was $3 \mathrm{~ms}$, the proximal test stimulus elicits a second recorded motor unit potential. When the stimulus interval was $2.8 \mathrm{~ms}$, as in fig 4D, the second response disappeared due to blocking during the axonal refractory period at the test point. Thus, the axonal refractory period for this motor unit was $3.0 \mathrm{~ms}$.

The axonal refractory periods following a conditioning electrical stimulus ranged from 1.8 to $3.5 \mathrm{~ms}$. For $30 \%(6 / 20)$ of the motor units the refractory period was longer than $3 \mathrm{~ms}$ which was observed in only $5 \%(2 / 27)$ of normal motor units. ${ }^{7}$ The mean value was $2.69 \pm 0.61 \mathrm{~ms}$. This was longer than the corresponding value in normal subjects, which was $2.38 \pm 0.24 \mathrm{~ms}$, but the difference was not statistically significant.

The refractory period after a conditioning electrical nerve stimulus was always longer than after a propagated nerve impulse (mean $0.36 \pm 0.25$ ), which was also found normally.? 


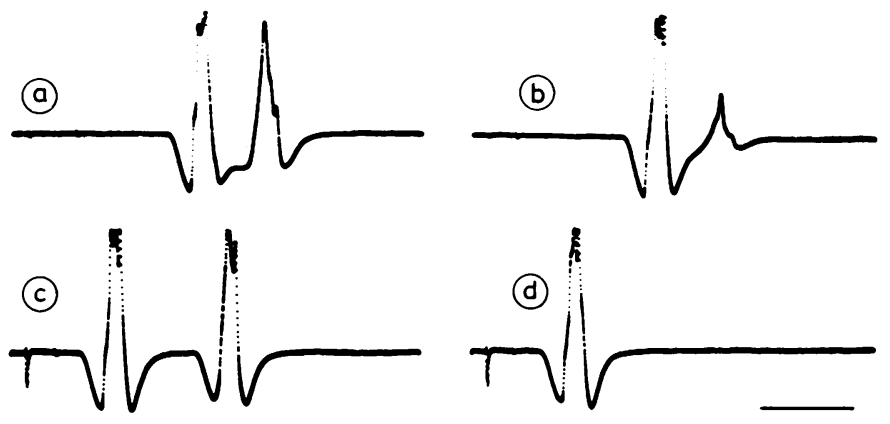

Fig 4 Single motor unit recordings when, in $A-B$, paired stimuli were delivered proximally to the peroneal nerve and, in $C-D$, when the same paired, proximal stimuli were delivered together with one distal stimulus to coincide with the first proximal stimulus. Further description in text. Time bar $10 \mathrm{~ms}$.

\section{Discussion}

The axonal conduction velocity and refractory period of single motor units in motor neuron disease have not been studied previously. In the present study, $50 \%$ of the motor units in patients with severe motor neuron disease were abnormal in one or both parameters. The most conspicuous finding was that $32 \%$ of the motor units had an abnormally long axonal refractory period but normal axonal conduction velocity. It cannot be determined whether this finding in patients with advanced motor neuron disease is due to a primary disease mechanism or to secondary changes. Further studies at different stages of the disease might be of value to establish this.

In the present study the axonal refractory period was determined both after a conditioning propagated nerve impulse and after a conditioning electrical nerve stimulus. Low test stimulus strength was used to minimise stimulus pain. The difference between the results obtained by the two methods was of the same magnitude as observed normally.?

When paired stimuli were delivered proximally to the peroneal nerve it was found that, for about one third of the motor units tested, the shortest motor unit response interval was longer than that observed normally. ${ }^{6}$ It is well known that the conduction velocity of an impulse propagated during the relative refractory period of a prior impulse is subnormal. ${ }^{610}$ Thus, the prolonged motor unit response interval is probably mainly due to prolonged axonal refractory period.

For another third of the motor units tested, the second evoked motor unit potential was successively broken down at shorter stimulus intervals due to peripheral blockings. This is in accordance with previous findings in motor neuron disease that the safety factor of the peripheral propagation is lower than normal."

The occurrence of peripheral blocking and delay of the second motor unit response even at stimulus intervals longer than $5 \mathrm{~ms}$ should be considered when the refractory period of peripheral motor nerve trunks is measured by using blocking techniques as described by Kimura. ${ }^{12}$ If the nerve segment between the distal blocking stimulus point and the proximal testing stimulus point is short, the interval between the muscle responses due to the distal stimulus and the testing stimulus might be critical. Thus a decrease of the test muscle action potential might be falsely interpreted as due to refractoriness of the nerve fibres at the test point.

Eighteen per cent of the investigated alpha motor axon had abnormally low axonal conduction velocity, several extremely low. The most probably explanation of this is that these are nerve fibres undergoing secondary degeneration. Since sprouting of nerve fibres due to denervation is not considered to occur outsie the muscle, ${ }^{13}$ there is no reason to believe that the slow conducting fibres are long nerve sprouts.

Previous studies of the conduction velocity spectrum of peripheral motor nerve trunks in motor neuron disease using collision techniques did not reveal a slow conducting nerve fibre population. ${ }^{14}$ is This might be due to insensitivity of these techniques using surface recordings of the compound muscle action potential or to different materials.

In summary this study has shown that there are electrophysiological signs of axonopathy in motor neuron disease when single motor units are investigated. About one third of the motor units have an abnormally long axonal refractory period but normal axonal conduction velocity. Whether this reflects a basic pathophysiological mechanism or secondary changes remains to be established.

\section{References}

${ }^{1}$ Lambert EH. Diagnostic value of electrical stimulation of motor nerves. Electroencephalogr Clin 
Neurophysiol 1962;Suppl 22:9-16.

${ }^{2}$ Spencer PS, Schaumburg HH. The pathogenesis of motor neuron disease: perspective from neurotoxicology. In: Rowland LP, ed. Advances in Neurology. New York: Raven Press, 1982;36:249-66.

${ }^{3}$ Dyck PH. Are motor neuropathies and motor neuron diseases separable? In: Rowland LP, ed. Advances in Neurology. New York: Raven Press, 1982;36:105-13.

${ }^{4}$ Borg J, Grimby L, Hannerz J. Axonal conduction velocity and voluntary discharge properties of individual short toe extensor motor units in man. J Physiol (Lond) 1978;277:143-52.

${ }^{5}$ Borg J. Axonal refractory period of single short toe extensor motor units in man. J Neurol Neurosurg Psychiatry 1980;43:917-24.

${ }^{6}$ Borg J. Effects of prior activity on the conduction in single motor units in man. J Neurol Neurosurg Psychiatry 1983;46:317-21.

${ }^{7}$ Borg J. Refractory period of single motor nerve fibres in man. J Neurol Neurosurg Psychiatry. (in press).

${ }^{8}$ Borg J. Properties of single extensor digitorum brevis motor units in elderly man. Muscle and Nerve 1981;4:429-34.

9 Tasaki J. Nervous Transmission. Springfield: Thomas, 1953.

${ }^{10}$ Gilliatt RW, Willison RG. The refractory and supernormal periods of the human median nerve. J Neurol Neurosurg Psychiatry 1963;26:136-47.

${ }^{11}$ Mulder DW, Lambert EH, Eato LM. Myasthenic syndrome in patients with amyotrophic lateral sclerosis. Neurology (Minneap) 1959;9:627-31.

12 Kimura JA. Method for estimating the refractory period of motor fibres in human peripheral nerve. $J$ Neurol Sci 1976;28:485-90.

${ }^{13}$ Brown MC, Holland RL. Hopkins WG. Motor nerve sprouting. Ann Rev Neurosci 1981;4:17-42.

${ }^{14}$ Miglietta O. Motor nerve fibres in amyotrophic lateral sclerosis. Am J Phys Med 1968;47:118-24.

${ }^{15}$ Chaco J. Conduction velocity of motor nerve fibres in progressive spinal atrophy. Acta Neurol (Scand) 1970;46:119-22. 